УДК 330.131 .7

\author{
Гайнуллин Ильдар Ильгизович, Руднева Юлия Ринатовна
}

\title{
ОЦЕНКА ВЛИЯНИЯ РИСК-МЕНЕДЖМЕНТА НА ЭФФЕКТИВНОСТЬ ПРОЕКТА ПО ВВЕДЕНИЮ ИНИЦИАТОРОВ В ПРОЦЕСС ПИРОЛИЗА БЕНЗИНОВОГО СЫРЬЯ
}

В статье представлены результаты исследования эффективности введения в процесс пиролиза бензинового сырья инициатора олефин-октена-1. Как при любом нововведении, изменение параметров нефтехимического прочесса приводит к дополнительным рискам. В работе составлена карта рисков использования предложсеного инициатора с выделением трех зон рисков по вероятности и степени уцерба. K наиболее значимым отнесены проектные риски, дифференцированнье в зависимости от температуры процесса пиролиза. Для предотвращения возникновения и негативных последствий ключевых рисков предложен комплекс мероприятий с оцененной общей стоимостью 10,6 мли руб. Их реализация ухудиает статические показатели эффективности проекта. Однако снижение практически всех видов риска проекта позволяет уменьиить ставку дисконтирования. В результате чистый дисконтированный доход вырос более чем на $30 \%$, что подтвержсено расчетами.

Ключевые слова: инициатор прочесса пиролиза, производственные риски, ставка дисконтирования, показатели эффективности, зоны риска.

\section{Ildar Gainullin, Yulia Rudneva \\ ASSESSMENT OF THE RISK MANAGEMENT INFLUENCE \\ ON THE EFFICIENCY OF THE INITIATORS APPLICATION \\ IN THE GASOLINE RAW MATERIAL PYROLYSIS}

The article presents the results of a study of the effectiveness of introducing the olefin-octene-1 initiator into the pyrolysis process of gasoline feedstocks. Like any innovation, changing the parameters of the petrochemical process leads to additional risks. The paper compiles a risk map of the proposed initiator applying with the allocation of three risk zones in terms of probability and damage degree. The most significant are project risks differentiated depending on the pyrolysis process temperature. To prevent the occurrence and negative consequences of key risks, a set of measures is proposed with an estimated total cost of 10.6 million rubles. Their implementation worsens the static performance indicators of the project. However, the reduction of almost all types of project risk allows reducing the discount rate. As a result, net present value increased by more than $30 \%$, which is confirmed by calculations.

Key words: pyrolysis process initiator, production risks, discount rate, performance indicators, risk zones.

Bведение /Introduction. В связи с ежегодным ростом объемов производства полиэтилена, полипропилена и других веществ, сырьем для которых являются продукты процесса пиролиза, актуальной является проблема увеличения производительности существующих мощностей нефтехимических производств, а также увеличение выхода целевых продуктов.

Одним из перспективных направлений модернизации процесса пиролиза является применение инициаторов [1]. Инициаторы - это специально вводимые вешества, которые запускают химические процессы.

Для проведения исследования в качестве инициатора выбран олефин-октен-1 по следующим причинам:

- $\quad$ выявлено, что вопрос влияния олефинов в качестве инициаторов на процесс пиролиза исследован недостаточно глубоко; 
- $\quad$ фракции олефинов являются продуктами процесса пиролиза, следовательно, в перспективе возможна рециркуляция части продуктов процесса в качестве инициаторов;

- относительная дешевизна олефинов, если они получаются в процессе пиролиза.

Технические характеристики лабораторной установки пиролиза представлены в таблице 1.

Таблица 1

Технические характеристики установки пиролиза

\begin{tabular}{|l|c|}
\hline \multicolumn{1}{|c|}{ Характеристики } & Значения \\
\hline Максимальная рабочая температура в реакторе (печи), оС & 850 \\
\hline Максимальное рабочее давление, бар (атм) & 8 \\
\hline Установленная мощность электропитания, кВт & 12,0 \\
\hline $\begin{array}{l}\text { Объем трубчатого реактора (печи): } \\
\text { общий объем } \\
\text { - рабочий объем }\end{array}$ & 7,6 мл \\
\hline
\end{tabular}

В данном исследовании поставлена первая цель: провести анализ влияния введения инициатора олефин-октена-1 на выходные параметры процесса пиролиза. Кроме того, следует отметить, что нефтехимические процессы характеризуются повышенным уровнем взрыво- и пожароопасности. Особенно это существенно для процессов пиролиза, протекающих при высоких температурах и давлении. Поэтому любое изменение технических характеристик является источником дополнительного риска.

В связи с этим следующей целью исследования является выявление и оценка возникающих дополнительных рисков реализации процесса пиролиза при введении инициаторов, а также разработка рекомендаций по их снижению. В результате проведена сравнительная оценка экономической эффективности проекта по введению инициатора олефи-октена- 1 в процесс пиролиза до и после реализации предложенных рекомендаций риск-менеджмента.

Maтериалы и методы / Materials and methods. Сравнение выхода пирогаза (V) при изменении температуры процесса (T) в присутствии и отсутствии инициатора приведено в таблице 2.

Таблица 2

Сравнение выхода пирогаза при изменении температуры процесса в присутствии и в отсутствии инициатора, л

\begin{tabular}{|c|c|c|c|}
\hline \multirow{2}{*}{$\begin{array}{c}\text { Tемпература процесса, } \\
{ }^{\circ} \mathbf{C}\end{array}$} & $\begin{array}{c}|c| \\
\text { в пыходугствии } \\
\text { инициатора }\end{array}$ & $\begin{array}{c}\text { в отсутствии } \\
\text { иницитора }\end{array}$ & $\begin{array}{c}\text { Увеличение выхода } \\
\text { пирогаза, \% }\end{array}$ \\
\hline 760 & 5,6 & 5,9 & 5,08 \\
\hline 780 & 7,4 & 8,4 & 11,90 \\
\hline 800 & 8,4 & 10,2 & 17,65 \\
\hline 820 & 8,6 & 9,8 & 12,24 \\
\hline
\end{tabular}

В ходе исследования влияния выбранного инициатора октена-1 на состав продуктов процесса пиролиза бензинового сырья сформулированы следующие выводы:

1) добавление инициатора - октена-1 в состав реакционной массы приводит к увеличению выхода пирогаза на 5,08-17,65 \% (об.), по сравнению с составом продуктов пиролиза при тех же условиях процесса без добавления инициатора;

2) добавление октена-1 в качестве инициатора в реакционную массу процесса пиролиза не влияет на состав жидких продуктов пиролиза. Концентрация бензола и толуола в опытах с одинаковыми параметрами с добавлением и без добавления инициатора практически не изменяется; 
3) предполагается, что качественный состав пирогаза также не изменяется. Это подтверждают литературные данные по инициированию процесса пиролиза бензинового сырья другими олефинами, а также результаты анализа качественного состава жидких продуктов.

Для обоснования целесообразности реализации предлагаемого технологического решения проведено сравнение технико-экономических показателей установки процесса пиролиза бензинового сырья до и после применения технологического решения (таблица 3).

Сравнение основных показателей базового и проектного вариантов исполнения

Таблица 3 процесса пиролиза бензинового сырья

\begin{tabular}{|l|c|c|c|c|}
\hline \multicolumn{1}{|c|}{ Показатель } & $\begin{array}{c}\text { Базовый } \\
\text { вариант }\end{array}$ & $\begin{array}{c}\text { Проектный } \\
\text { вариант }\end{array}$ & $\begin{array}{c}\text { Абсолютное } \\
\text { изменение }\end{array}$ & $\begin{array}{c}\text { Относите.льоее } \\
\text { изменение, \% }\end{array}$ \\
\hline $\begin{array}{l}\text { Выход основных продуктов: } \\
\text { - Этилен, тыс. т. }\end{array}$ & $\begin{array}{l}79,49 \\
\text { Пропилен, тыс. т. }\end{array}$ & $\begin{array}{l}83,89 \\
45,41\end{array}$ & $\begin{array}{c}4,40 \\
10,89\end{array}$ & 31,54 \\
\hline $\begin{array}{l}\text { Стоимость продукции по ценам } \\
\text { предприятия, млн руб. }\end{array}$ & 4490,86 & 4530,36 & 43,63 & 0,97 \\
\hline $\begin{array}{l}\text { Себестонмость всего выпуска, } \\
\text { млн руб. }\end{array}$ & 3893,12 & 3905,72 & 16,16 & 0,42 \\
\hline $\begin{array}{l}\text { Прибыль от реализации } \\
\text { продукции, млн руб. }\end{array}$ & 600,17 & 624,64 & 24,47 & 4,60 \\
\hline
\end{tabular}

Таким образом, в проектном варианте исполнения процесса пиролиза бензинового сырья происходит увеличение выхода этилена и пропилена на 5,54 и 31,54 \%.

Если рассматривать предложенную модификацию с точки зрения замещения ППФ, закупаемого с НПЗ, пропиленом с установки пиролиза бензинового сырья, то происходит экономия денежных средств в размере равном 39,46 млн руб. в год.

Внедрение инициированного пиролиза приводит к увеличению годовой прибыли от реализации продукции на 4,60\% по сравнению с базовым вариантом установки.

В проектном варианте также увеличивается себестоимость продукции вследствие увеличения затрат на перекачку и топливо для печей пиролиза из-за увеличения загрузки на $2 \%$ масс. по отношению к бензиновому сырью при добавлении инициатора в реакционную массу.

Увеличение выхода пирогаза варьируется с изменением температуры реакции пиролиза бензинового сырья. Поэтому стоит закладывать различные значения премии за риск для каждого значения температуры процесса.

В связи с этим предлагается следующий алгоритм определения показателей эффективности инвестирования в проект:

1) определение проектной температуры процесса пиролиза бензинового сырья;

2) расчет материального баланса для выбранных параметров процесса;

3) расчет калькуляции себестоимости, технико-экономических показателей процесса;

4) расчет ставки дисконтирования, премия за конструкторский риск выбирается исходя из выбранной в пункте 1 температуры;

5) расчет показателей эффективности проекта при полученных ставках дисконтирования.

В процессе реализации проекта внедрения инициированного пиролиза бензинового сырья в действующие мощности процесса необходимо оценивать возможные негативные последствия, возникающие при использовании нововведения в процесс.

Для этого используется анализ рисков проекта, являющийся составной частью комплексного обоснования инвестиционного проекта. Также анализ риска является связующим звеном между процессом обоснования инвестиционного проекта и управлением его реализацией [2]. 
На этапе подготовки к модернизации действующих установок процесса пиролиза бензинового сырья, а также на этапе строительно-монтажных работ возникают предпроизводственные риски.

Предпроизводственные риски - риски, обусловленные ошибками, просчетами в предпроизводственный период.

Риск несвоевременного завершения строительства - риск, обусловленный следующими причинами [3]:

- просчеты в проектировании, ошибки в проектно-сметной документации;

- недостаточная квалификация и опыт проектной и подрядной организаций;

- нарушение обязательств проектной и подрядной организаций;

- отсутствие в договорах с проектными и подрядными организациями ответственности за срыв сроков работ.

Риск превышения сметной стоимости проекта - риск, обусловленный следующими причинами:

- просчеты в проектировании, ошибки в проектно-сметной документации;

- неспособность подрядчика обеспечить эффективное использование ресурсов;

- изменение условий реализации проекта (повышение цен, увеличение налогов и др.);

- недостаточная изученность объектов инвестирования.

Риск низкого качества работ (объекта) - риск, обусловленный следующими причинами:

- нарушение обязательств подрядчиком и (или) поставщиком материалов и оборудования;

- $\quad$ малый опыт подрядчика;

- ведение подрядчиком работ на нескольких объектах;

- ошибки на стадии строительства;

- неоправданное стремление к экономии финансовых и материальных ресурсов;

- $\quad$ нереальность графика проведения строительно-монтажных работ (этапность, планирование одновременного ведения нескольких видов работ);

- некачественные условия доставки и хранения основных материалов и оборудования.

Также важно произвести анализ рисков, возникающих после строительно-монтажных работ на этапе эксплуатации модернизированной установки.

Pезультаты и обсуждение / Results and discussion. Наиболее характерные риски, возникающие при внедрении проекта инициированного пиролиза бензинового сырья, приведены в таблице 4.

На характеристики процесса введение предложенного инициатора не влияет, поэтому не рассматриваем риски реализации технологического процесса. Рассматриваем только риски, связанные с введением инициатора в реакционную массу процесса пиролиза бензинового сырья.

Таблица 4

Наиболее значимые риски внедрения инициатора в процесс пиролиза бензинового сырья

\begin{tabular}{|c|c|c|c|}
\hline $\begin{array}{l}\text { Наименование } \\
\text { риска }\end{array}$ & Причины возникновения риска & $\begin{array}{c}\text { Вероятность } \\
\text { возникновения } \\
\text { риска }\end{array}$ & $\begin{array}{l}\text { Степень } \\
\text { ущерба }\end{array}$ \\
\hline \multicolumn{4}{|c|}{ Предпроизводственные риски } \\
\hline \multirow{2}{*}{$\begin{array}{l}\text { Риск } \\
\text { несвоевременного } \\
\text { завершения } \\
\text { строительства }\end{array}$} & $\begin{array}{l}\text { Риск 1. Просчеты в проектировании, ошиб- } \\
\text { ки в проектно-сметной документации }\end{array}$ & Средняя & Средняя \\
\hline & $\begin{array}{l}\text { Риск 2. Недостаточная квалификация и } \\
\text { опыт проектной организации }\end{array}$ & Средняя & Средняя \\
\hline \multirow{2}{*}{$\begin{array}{l}\text { Риск превышения } \\
\text { сметной стоимости } \\
\text { проекта }\end{array}$} & $\begin{array}{l}\text { Риск 3. Неспособность подрядчика обеспе-- } \\
\text { чить эффективное использование ресурсов; }\end{array}$ & Средняя & Низкая \\
\hline & Риск 4. Малый опыт подрядчика & Низкая & Средняя \\
\hline
\end{tabular}




\begin{tabular}{|c|c|c|c|}
\hline $\begin{array}{c}\text { Наименование } \\
\text { риска }\end{array}$ & Причины возникновения риска & $\begin{array}{c}\text { Вероятность } \\
\text { возникновения } \\
\text { риска } \\
\end{array}$ & $\begin{array}{l}\text { Степень } \\
\text { ущерба }\end{array}$ \\
\hline \multicolumn{4}{|c|}{ Производственные (проектные) } \\
\hline \multirow[t]{3}{*}{$\begin{array}{l}\text { Конструкционный } \\
\text { (технологический) } \\
\text { риск }\end{array}$} & $\begin{array}{l}\text { Риск 5. Ошибки в проектировании, недо- } \\
\text { стижение запланированных технических } \\
\text { параметров, выходов целевых продуктов } \\
\text { в результате применения инициаторов на } \\
\text { промышленной установке (расхождение } \\
\text { лабораторных и фактических результатов } \\
\text { применения инициаторов): зависит от тем- } \\
\text { пературы процесса и ожидаемого при этой } \\
\text { температуре повышения выхода пирогаза: } \\
\text { - Риск } 5 \mathrm{~A}-760^{\circ} \mathrm{C}-5,08 \% \\
\text { - Риск } 5 \mathrm{5}-780^{\circ} \mathrm{C}-11,90 \% \\
\text { - Риск } 5 \mathrm{~B}-800^{\circ} \mathrm{C}-17,65 \% \\
\text { - Риск } 5 \Gamma-820^{\circ} \mathrm{C}-12,24 \% \\
\end{array}$ & $\begin{array}{l}\text { Низкая } \\
\text { Средняя } \\
\text { Высокая } \\
\text { Средняя }\end{array}$ & $\begin{array}{l}\text { Высокая } \\
\text { Высокая } \\
\text { Высокая } \\
\text { Высокая }\end{array}$ \\
\hline & $\begin{array}{l}\text { Риск } 6 . \text { Возникновение при использовании } \\
\text { инициаторов побочных или отсроченных } \\
\text { во времени проявления проблем: увеличе- } \\
\text { ние износа реакторного, теплообменного } \\
\text { оборудования, трубопроводов вследствие } \\
\text { применения инициатора }\end{array}$ & Средняя & Средняя \\
\hline & $\begin{array}{l}\text { Риск } 7 . \text { Низкие технологические возможно- } \\
\text { сти производства, что не позволяет освоить } \\
\text { результаты новых разработок: технические } \\
\text { особенности модернизируемой установки, } \\
\text { общий износ оборудования, которые не } \\
\text { позволят произвести внедрение технологии } \\
\text { инициированного пиролиза; }\end{array}$ & Низкая & Низкая \\
\hline Экологический риск & $\begin{array}{l}\text { Риск 8. Нарушение подрядчиками, предпри- } \\
\text { ятием экологических стандартов в процессе } \\
\text { строительно-монтажных работ, а также в } \\
\text { процессе эксплуатации модернизированно- } \\
\text { го производства; }\end{array}$ & Низкая & Высокая \\
\hline
\end{tabular}

Для визуального предоставления анализа и оценки рисков проекта внедрения инициированного пиролиза бензинового сырья построена матрица характерных для проекта рисков. Матрица рисков проекта представлена в таблице 5.

Таблица 5

Матрица рисков проекта

\begin{tabular}{|c|c|c|c|}
\hline \multirow{2}{*}{ Степень ущерба } & \multicolumn{3}{|c|}{ Вероятность } \\
\cline { 2 - 4 } & Низкая & Средняя & Высокая \\
\hline Высокая & $\mathbf{5 A , 8}$ & $5 \mathrm{5}, 5 \Gamma$ & $5 \mathrm{~B}$ \\
\hline Средняя & 4 & $1,2,6$ & \\
\hline Низкая & 3,7 & 3 & \\
\hline
\end{tabular}

На матрице все риски располагаются в разных цветовых зонах:

- белая - эти риски не требуют особых мер по устранению, необходим только мониторинг;

- серая - риски, которые являются достаточно приемлемыми, но желательно их снижение за счет мероприятий риск-менеджмента;

- $\quad$ темно-серая - это неприемлемые риски, которые прямо угрожают проекту. Они требуют обязательного воздействия риск-менеджеров. 
Конструкционный (технический) риск является наиболее вероятным вследствие, что можно не достичь запланированных технических параметров, выходов целевых продуктов в результате применения инициаторов на промышленной установке. Возможно расхождение лабораторных и фактических результатов применения инициаторов в увеличении выхода пирогаза в проектном варианте процесса.

Конструкционные (технические) риски 5Б, 5В, 5Г находятся в зоне неприемлемых рисков, угрожающих проекту. В связи с этим необходима разработка мероприятий по снижению вероятности и ущерба от наступления этих рисковых ситуаций.

Таким образом, проект получает оценку рисков, неприемлемую для его реализации. Для предотвращения возникновения и негативных последствий ключевых рисков был разработан комплекс мероприятий и оценены затраты на их реализацию (таблица 6). Общая сумма составила 10,6 млн руб.

Наибольшие усилия были направлены на снижение конструкционного риска. Рекомендуется на этапе подготовки проекта

- провести дополнительные исследования влияния выбранного инициатора на сырье установки пиролиза, на которой планируется модернизация;

- реализовать компьютерное моделирование процесса;

- провести предварительные опыты на одной действующей печи пиролиза.

Таблица 6

Мероприятия по управлению рисками проекта

\begin{tabular}{|c|c|c|c|c|}
\hline Наименование риска & $\begin{array}{c}\text { Причины } \\
\text { возникновения } \\
\text { риска }\end{array}$ & $\begin{array}{l}\text { Мероприятия по снижению } \\
\text { негативных последствий }\end{array}$ & $\begin{array}{l}\text { Затраты, } \\
\text { м.лн р. }\end{array}$ & $\begin{array}{c}\text { Эффект } \\
\text { мероприятий }\end{array}$ \\
\hline \multicolumn{5}{|c|}{ Предпроизводственные риски } \\
\hline $\begin{array}{l}\text { Риск несвоевремен- } \\
\text { ного завершения } \\
\text { строительства }\end{array}$ & $\begin{array}{l}\text { Риск } 1 \\
\text { Риск } 2\end{array}$ & \multirow{2}{*}{ Резервирование средств } & \multirow{2}{*}{1,1} & \multirow{2}{*}{$\begin{array}{l}\text { Снижение } \\
\text { ущерба }\end{array}$} \\
\hline $\begin{array}{l}\text { Риск превышения } \\
\text { сметной стонмости } \\
\text { проекта }\end{array}$ & $\begin{array}{l}\text { Риск } 3 \\
\text { Риск } 4\end{array}$ & & & \\
\hline \multicolumn{5}{|c|}{ Производственные (проектные) } \\
\hline $\begin{array}{l}\text { Конструкционный } \\
\text { (технологический) } \\
\text { риск }\end{array}$ & $\begin{array}{l}\text { Риски } \\
\text { 5А, 5Б, 5В, 5Г } \\
\text { Риск } 6 \\
\text { Риск } 7\end{array}$ & $\begin{array}{l}\text { - дополнительные исследо- } \\
\text { вания влияния выбранного } \\
\text { инициатора на сырье уста- } \\
\text { новки пиролиза, на которой } \\
\text { планируется модернизация; } \\
\text { использование компью- } \\
\text { терного моделирования } \\
\text { процесса; } \\
\text { - проведение дополнитель- } \\
\text { ных опытов на действую- } \\
\text { щей установке на одной } \\
\text { печи пиролиза; } \\
\text { резервирование средств }\end{array}$ & $\begin{array}{l}0,1 \\
0,5\end{array}$ & $\begin{array}{c}\text { Снижение } \\
\text { вероятности } \\
\text { и ущерба }\end{array}$ \\
\hline \multirow[t]{2}{*}{ Экологический риск } & Риск 8 & Страхование риска & 1,0 & $\begin{array}{l}\text { Снижение } \\
\text { ущерба }\end{array}$ \\
\hline & Всего & & 10,6 & \\
\hline
\end{tabular}

Таким образом, на мероприятия по снижению негативных последствий рисков проекта внедрения инициированного пиролиза бензинового сырья предлагается затратить 10,6 млн руб. 
Матрица рисков проекта после применения мероприятий по снижению негативных последствий представлена в таблице 7.

Таблича 7

Матрица рисков проекта после применения мероприятий по управлению рисками

\begin{tabular}{|c|c|c|c|}
\hline \multirow{2}{*}{ Степень ущерба } & \multicolumn{3}{|c|}{ Вероятность } \\
\cline { 2 - 4 } & Низкая & Средняя & Высокая \\
\hline Высокая & & & \\
\hline Средняя & $\mathbf{5 A , ~}, \boldsymbol{\Gamma}, \mathbf{8}$ & $\mathbf{5 ~ B}$ & \\
\hline Низкая & $\mathbf{6 , 7}$ & $\mathbf{1 , 2 , 3 , 4}$ \\
\hline
\end{tabular}

Таким образом, в результате реализации предложенных мероприятий риск-менеджмента из черной зоны «ушли» все риски. В серой зоне остался только один риск. Все остальные риски оказались в белой зоне, т. е. существенно снизилась либо вероятность их наступления, либо степень нанесенного ущерб́а.

Однако необходимо учесть, что дополнительно понесенные затраты негативно повлияют на эффективность реализации проекта. Оценку влияния данного факта проведем далее.

Заключение / Conclusion. Для оценки влияния реализации предложенных мероприятий по снижению риска и дополнительных затрат на проект был проведен сравнительный анализ показателей эффективности проекта до и после их внедрения (таблица 8).

Таблица 8

Оценка премии за риск до и после применения мероприятий по снижению рисков

\begin{tabular}{|c|c|c|c|c|}
\hline \multirow{2}{*}{ Наименование риска } & \multirow{2}{*}{$\begin{array}{c}\text { Причины возникновения } \\
\text { риска }\end{array}$} & \multicolumn{3}{|c|}{ Премия за риск, \% } \\
\hline & & до & после & изменение \\
\hline \multicolumn{5}{|c|}{ Предпроизводственные риски } \\
\hline $\begin{array}{l}\text { Риск несвоевременного } \\
\text { завершения строительства }\end{array}$ & $\begin{array}{l}\text { Риск } 1 \\
\text { Риск } 2\end{array}$ & $\begin{array}{l}1 \\
1\end{array}$ & $\begin{array}{l}0 \\
0\end{array}$ & $\begin{array}{l}-1 \\
-1\end{array}$ \\
\hline $\begin{array}{l}\text { Риск превышения сметной } \\
\text { стоимости проекта }\end{array}$ & $\begin{array}{l}\text { Риск } 3 \\
\text { Риск } 4\end{array}$ & $\begin{array}{l}1 \\
1\end{array}$ & $\begin{array}{l}0 \\
0\end{array}$ & $\begin{array}{l}-1 \\
-1\end{array}$ \\
\hline \multicolumn{5}{|c|}{ Производственные (проектные) } \\
\hline $\begin{array}{l}\text { Конструкционный } \\
\text { (технологический) риск }\end{array}$ & $\begin{array}{c}\text { Риск 5А } \\
\text { Риск 5Б } \\
\text { Риск 5В } \\
\text { Риск 5Г } \\
\text { Риск } 6 \\
\text { Риск } 7\end{array}$ & $\begin{array}{l}1 \\
2 \\
3 \\
2 \\
1 \\
1\end{array}$ & $\begin{array}{l}0 \\
1 \\
2 \\
1 \\
0 \\
0\end{array}$ & $\begin{array}{l}-1 \\
-1 \\
-1 \\
-1 \\
-1 \\
-1 \\
\end{array}$ \\
\hline Экологический риск & Риск 8 & 1 & 1 & 0 \\
\hline
\end{tabular}

Оценка эффективности была проведена для всех четырех проектных температурных режимов процесса пиролиза (таблица 9).

\section{Сравнительный анализ показателей эффективности проекта} до и после внедрения мероприятий по снижению рисков

\begin{tabular}{|c|c|c|c|c|c|}
\hline \multicolumn{2}{|c|}{ Температурный режим } & \multicolumn{4}{|c|}{ Показатель } \\
\cline { 3 - 6 } & & NPV & PI & DPP, мес. & IRR, \% \\
\hline \multirow{3}{*}{$\mathrm{t}=760^{\circ} \mathrm{C}$} & до & 109,29 & 10,75 & 7 & 244 \\
\cline { 2 - 6 } & после & 146,93 & 7,73 & 12 & 155 \\
\cline { 2 - 6 } & изменение & 37,64 & $-3,02$ & 5 & -89 \\
\hline
\end{tabular}




\begin{tabular}{|c|c|c|c|c|c|}
\hline \multirow{2}{*}{\multicolumn{2}{|c|}{ Температурный режим }} & \multicolumn{4}{|c|}{ Показатель } \\
\hline & & \multirow{2}{*}{$\begin{array}{c}\text { NPV } \\
109,81\end{array}$} & \multirow{2}{*}{$\begin{array}{c}\text { PI } \\
10,80\end{array}$} & \multirow{2}{*}{$\begin{array}{c}\text { DPP, мес. } \\
7\end{array}$} & \multirow{2}{*}{$\begin{array}{c}\text { IRR, \% } \\
251\end{array}$} \\
\hline \multirow{3}{*}{$\mathrm{t}=780^{\circ} \mathrm{C}$} & до & & & & \\
\hline & после & 145,83 & 7,69 & 12 & 159 \\
\hline & изменение & 36,02 & $-3,11$ & 5 & -92 \\
\hline \multirow{3}{*}{$\mathrm{t}=800^{\circ} \mathrm{C}$} & до & 110,23 & 10,84 & 7 & 258 \\
\hline & после & 144,72 & 7,64 & 12 & 162 \\
\hline & изменение & 34,49 & $-3,2$ & 5 & -96 \\
\hline \multirow{3}{*}{$\mathrm{t}=820^{\circ} \mathrm{C}$} & до & 110,91 & 10,90 & 7 & 253 \\
\hline & после & 147,38 & 7,73 & 12 & 160 \\
\hline & изменение & 36,47 & $-3,17$ & 5 & -93 \\
\hline
\end{tabular}

Произведена оценка премии за риск после применения мероприятий по снижению рисков. Рассчитаны новые значения ставки дисконтирования после применения мероприятий. Ставка дисконтирования для всех температурных режимов снизилась на 7 единиц по сравнению с показателями до принятия мероприятий по снижению рисков.

По новым ставкам дисконтирования рассчитаны показатели эффективности проекта. Выполнен сравнительный анализ показателей эффективности проекта до и после внедрения мероприятий по снижению рисков.

Повышение затрат на реализацию проекта, связанных с управлением рисками, привело к негативному изменению индекса рентабельности, срока окупаемости и внутренней нормы доходности. Однако все они остались на уровне приемлемых для инвесторов.

В то же время за счет снижения рисков реализации проекта повысился один из самых существенных показателей - чистый дисконтированный доход: на 31,3-34,4 \%.

Данные результаты подтверждают эффективность предложенных рекомендаций по снижению риска проекта с точки зрения оценки влияния затрат на их реализацию на показатели инвестиционного проекта.

\section{ЛИТЕРАТУРА И ИНТЕРНЕТ-РЕСУРСЫ}

1. Салахов, И. И. Инициированный пиролиз прямогонного бензина / И. И. Салахов, А. Ш. Зиятдинов. Х. Х. Гильманов, А. М. Екимова, А. Ш. Бикмурзин, И. Н. Дияров // Химическая промышленность сегодня : сб. науч. тр. - Москва, 2005. - С. 16-24. - Текст : непосредственный.

2. Волков, П. М. Проектный анализ / П. М. Волков, М. В. Грачева. - Москва : ЮНИТИ, 2013. - 423 с. Текст : непосредственный.

3. Внешние факторы риска. - URL: https://center-yf.ru/data/Menedzheru/vneshnie-faktory-riska.php. Текст : электронный.

\section{REFERENCES AND INTERNET RESOURCES}

1. Salakhov, I. I. Initsiirovannyi piroliz pryamogonnogo benzina / I. I. Salakhov, A. Sh. Ziyatdinov, Kh. Kh. Gil'manov, A. M. Ekimova, A. Sh. Bikmurzin, I. N. Diyarov // Khimicheskaya promyshlennost' segodnya : sb. nauch. tr. - Moskva, 2005. S. 16-24.

2. Volkov, P. M. Proektnyi analiz / P. M. Volkov. - Moskva : YuNITI, 2013. - 423 s.

3. Vneshnie faktory riska [Elektronnyi resurs]. - URL: https://center-yf.ru/data/Menedzheru/vneshniefaktory-riska.php 


\section{СВЕДЕНИЯ ОБ АВТОРАХ}

Гайнуллин Ильдар Ильгизович, магистр химической технологии, магистр экономики, оператор технологических установок, ПАО «Уфаоргсинтез», г. Уфа, Российская Федерация. Е-mail: julrud1976@yandex

Руднева Юлия Ринатовиа, кандидат экон. наук, доцент, кафедра «Корпоративные финансы и учетные технологии», Уфимский государственный нефтяной технический университет, г. Уфа, Российская Федерация. E-mail: julrud1976@yandex.ru

\section{INFORMATION ABOUT AUTHORS}

Ildar Gainullin, Master of Chemical Technology, Master of Economics, process unit operator, PAO "Ufaorgsintez", Ufa, Russian Federation. E-mail: julrud1976@yandex.ru

Yulia Rudneva, Ph. D. Sci., Associate Professor, Department of Corporate Finance and Accounting Technologies, Ufa State Petroleum Technological University, Ufa, Russian Federation. E-mail: julrud1976@yandex.ru 